\title{
Durability of polydicyclopentadiene under high temperature, high pressure and seawater (offshore oil production conditions)
}

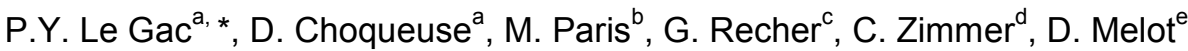

\author{
a IFREMER (French Ocean Research Institute), Centre de Brest, Materials and Structures Group, F-29280 \\ Plouzané, France \\ b Institut des Matériaux Jean Rouxel (IMN), Université de Nantes, CNRS, 2 rue de la Houssinière , BP 32229, \\ 44322 Nantes cedex 3, France \\ ${ }^{c}$ TELENE SAS, 2 rue Marie Curie, 59910 Bondues, France \\ ${ }^{d}$ DORIS Engineering, 58A rue du Dessous des Berges, 75013 Paris, France \\ e TOTAL SA, DGEP/DEV/TEC/COR/22D67, 2 place de la Coupole, 92078 Paris La Defence 6, France \\ *: Corresponding author : Pierre-Yves Le Gac, email address : pierre.yves.le.gac@ifremer.fr
}

\begin{abstract}
:
In the offshore industry polymer coatings are widely used to ensure thermal insulation of steel pipes, and to avoid over-cooling of the hot oil inside. Because of very severe service conditions (i.e. high temperature, high pressure and presence of seawater) and an expected life time of 20 years, durability of these coatings is a major issue for this industry. Polypropylene and polyurethane are often used for this application, nevertheless these polymers have some limitations in terms of processing time for polypropylene and maximum service temperature for polyurethane. Polycyclopentadiene (pDCPD) shows good processing characteristics and low thermal conductivity, so this polymer could be a good alternative coating in the offshore industry, but the durability of this polymer under offshore conditions is unknown. This paper present results from an accelerated ageing study of pDCPD in sea water at temperatures from $90^{\circ} \mathrm{C}$ to $180^{\circ} \mathrm{C}$ for 18 months. Polymer evolution during ageing is characterized using both mechanical (tensile test and DMA) and chemical (FTIR, NMR) analyses. For ageing at temperatures below $\mathrm{Tg}$ (i.e. $155^{\circ} \mathrm{C}$ ) the only degradation mechanism is oxidation, whereas for ageing temperatures above $\mathrm{Tg}$ secondary polymerization process of the material is observed.
\end{abstract}

Keywords: polyDiCycloPentaDiene ; Sea water ; Accelerated ageing ; Oxidation ; OffShore ; FieldJoint 


\section{Introduction}

Global increase in oil demand is extending the economic viability of oil fields to more severe conditions. This is especially true for the deep sea offshore industry where the water depths are increasing with oil increasingly difficult to extract, due to many factors such as oil composition, high temperature or distance from the floating production plant (Floating Production Storage and Offloading). When extracted, oil temperature can be up to $100^{\circ} \mathrm{C}$ and has to be transported to the FPSO using steel pipes in sea water at low temperature (basically $4^{\circ} \mathrm{C}$ ). To ensure extraction it is absolutely mandatory to limit the over-cooling of the oil both to avoid gas hydrate formation and also to increase productivity. A multi-material passive insulation layer is placed between the hot steel pipe and the cold sea water to limit thermal transfer between oil and water (Figure 1). During installation of a deep offshore field, coated steel pipes are joined together by welding. To ensure the continuity of the insulation along the flow line it is necessary to add an insulation layer over the weld (Figure 1), this section is known as a Field Joint (FJ). Field joints are complex from a material point of view : First, the material has to be a good thermal insulation polymer. Second, this polymer requires good adhesion to the multi-material layer used on steel pipe, with appropriate mechanical properties. And finally, this material need a good durability under severe conditions such as high temperature, high pressure and sea water. Currently there are two main solutions for this application, polyurethane is widely used but this polymer has some limitations in terms of durability under this conditions. In fact when PU's are used in hot water they undergoes hydrolysis even if they are based on polyether $[1,2]$. The second solution is polypropylene which presents better durability but has some process limitations.

DCPD (DiCycloPentaDiene) liquid engineered formulations designed for reaction injection molding (RIM) have been commercially available since the end of the 1980s. DCPD is a readily available diolefin monomer found in the off streams of petrochemical refineries. It has been used as a chemical intermediate for both flame retardant and EPDM elastomers. DCPD resins undergo polymerisation via ring opening metathesis polymerisation or an 


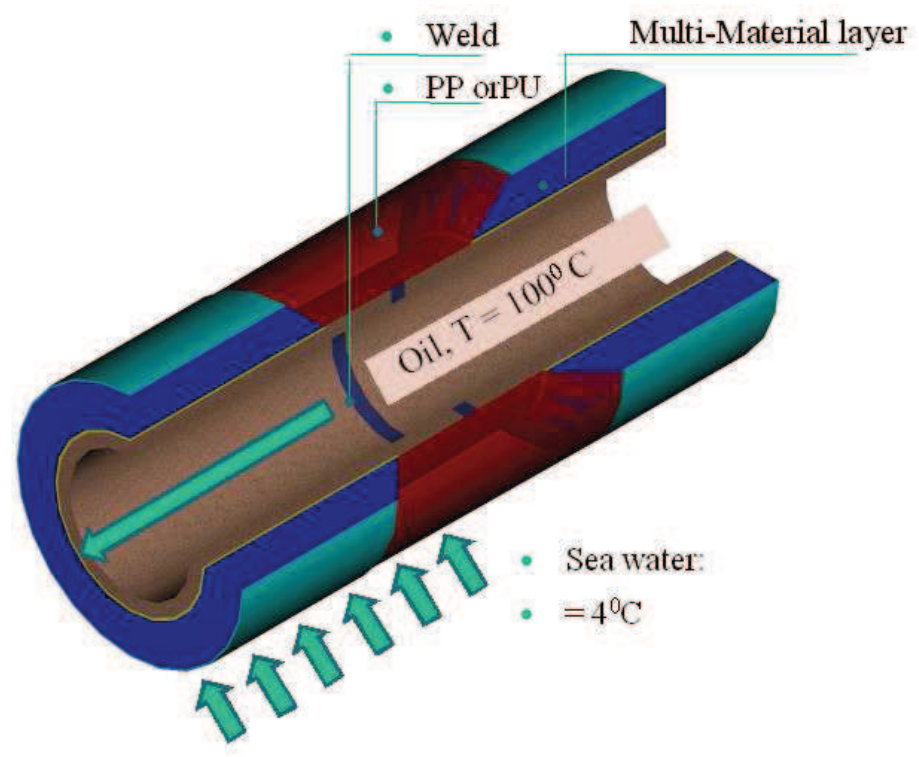

Figure 1: Schematic representation of a Field Joint

ROMP reaction, to give a tough, thermoset polymer. Typical commercially available DCPD resins are formulated in 2 components, A and B. Component A contains DCPD monomer, norbornene based comonomer, cocacatalyst and additives. Component $\mathrm{B}$ is almost identical to component $\mathrm{A}$, apart from containing an organometallic catalyst instead of the cocatalyst. The catalyst is often a chloride or an ammonium salt of a transition metal such as tungsten or molybdenum. The cocatalyst is usually an alkyl aluminium chloride. The reaction mechanism is based on metathesis chemistry. The reaction starts when catalyst and cocatalyst are combined by mixing A and B components. The active initiator of the reaction is a coordination type catalyst formed by the reaction of the metal compound with the alkyl aluminium chloride. The resulting complex then opens the highly strained norbornene ring. Propagation is by a metathesis mechanism through the norbornene. The reaction mechanism of the DCPD ROMP has been described elsewhere [3]. The less strained cyclopentene ring can also react leading to the cross-linked network [4]. The actual process of polymerization mechanism is a complex process and still not fully understood. The DCPD liquid formulation offers several characteristics that make it suitable to be processed by reaction injection molding: 
- Similar and low viscosity of both components, adjustable gel time allowing the moulding of large and complicated parts.

- Fast curing time, no need for mould release, except for parts presenting mechanical locking possibilities.

- Less sensitivity to stoichiometric ratio control than other RIM polymers.

Typical properties of a non reinforced $\mathrm{pDCPD}$ system are presented in Table 1. Due to its characteristics, it seems that pDCPD exhibits potential for the field joint application, but the question of the durability of this polymer in an offshore environment has to be assessed.

When immersed in sea water, a polymer absorbs water due to the difference in water concentration between the material and the external medium. In the case of Fickian behavior, the water diffusion in a polymer can be defined by the kinetics of diffusion (i.e. the water diffusion coefficient) and the content at saturation (i.e. solubility of water in the polymer) $[5,6]$. The presence of water will plasticize the polymer, this leads to a decrease of the $\mathrm{Tg}[7$, $6]$ but also a decrease of the material stiffness [8, 9]. At the same time, large aborption of water in a polymer will increase the thermal conductivity significantly [10], and thus decrease the thermal insulation properties of the coating in service. Due to temperature gradients in the insulation layer, it is necessary to assess water absorption at different temperatures to be able to predict the water content in the coating as a function of time. Water may also cause irreversible damage in polymers due to hydrolysis, especially at high temperature $[11,12,13,14,15,16]$, this point has to be adressed to evaluate the durability of this polymer under offshore conditions.

The aim of this study is to evaluate the durability of pDCPD for field joints in deep offshore applications. Because the service life required is 20 years, it is mandatory to performed accelerated ageing tests. Accelerated ageing was performed on polydicyclopentadiene in natural renewed sea water at temperatures from $90^{\circ} \mathrm{C}$ to $180^{\circ} \mathrm{C}$ under hydrostatic pressure for durations up to 18 months. The evolutions of chemical and mechanical properties have been investigated in order to assess the ageing mechanisms and consequences. Using these results it is possible to evaluate the durability of this polymer for field joint applications. 


\section{Methods}

\subsection{Material}

The DCPD resins are formulated as a stable two components system - A and $\mathrm{B}$ :

- Component A comprises DCPD monomer and norbornene based comonomers, co-catalyst and additives.

- Component B is more than 99\% identical to component A apart from containing an organo-metallic catalyst instead of the co-catalyst.

The samples used in this study have been produced from Telene 1650 formulation by Reaction Injection Moulding process (RIM) on a Cannon A40 RIM injection unit at 100 bars in the FPL 10 Mixhead with a 1 to 1 ratio. Raw material was injected at $25^{\circ} \mathrm{C}$ in an aluminium alloy mold at $75^{\circ} \mathrm{C}$. The catalyst of the metathesis polymerization is a molybdenum base salt and the cocatalyst is diethyl aluminium chloride. Some elastomers (EPDM about $3 \%$ ) are also included in the formulation in order to improve mouldability and flexibility of the formulation. The actual structure of the polymer is complex and represented in figure 2, overall cross link density of this material is $0.7 \mathrm{~mol} \cdot \mathrm{Kg}^{-1}$. This polymer does not have any ductile/brittle transition when tested at low temperature.

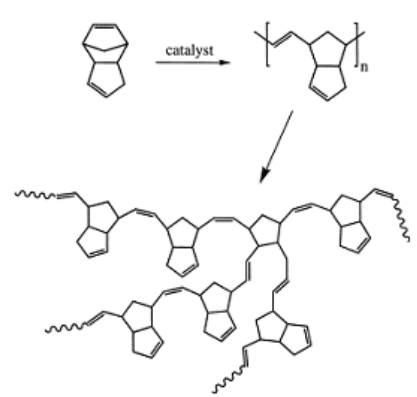

Figure 2: Structure of cross-linked polydicyclopentadiene [17] 


\begin{tabular}{|c|c|}
\hline Properties & Value \\
\hline Tg & $155^{\circ} \mathrm{C}$ \\
Tensile modulus & $1.8 \mathrm{GPa}$ \\
Elongation at yield & $5 \%$ \\
Thermal Conductivity & $0.17 \mathrm{~W} / \mathrm{m} . \mathrm{K}$ \\
\hline
\end{tabular}

Table 1: Main properties of the pDCPD used in this study

\subsection{Accelerated Ageing}

Accelerated ageing was performed in natural renewed sea water at 5 different temperatures from $90^{\circ} \mathrm{C}$ to $180^{\circ} \mathrm{C}$ for up to 18 months. Accelerating factors are both temperature and water accessability. In fact during these ageing tests, polymer is directly in contact with hot sea water whereas in service water has to diffuse from the cold external surface to the inside of the coating. For temperatures above $90^{\circ} \mathrm{C}$, ageing was also performed under hydrostatic pressure of 200 bar. Aged samples were removed periodically from ageing tanks in order to perform characterization.

\subsection{Weight change}

The weight changes of square samples $(5 \mathrm{~cm} * 5 \mathrm{~cm})$ with two different thicknesses (3 and $5 \mathrm{~mm}$ ) were followed by periodic weighing on a Sartorius LA $310 \mathrm{~S}$ balance (precision $0.1 \mathrm{mg}$ ). Samples were removed from the ageing containers and wiped with paper towels before weighing to dry the surfaces. The mass $\mathrm{M}$ of each sample at time $\mathrm{t}$ is expressed as a percentage as

$$
M(t)=\frac{m(t)-m o}{m o} * 100
$$

With mo the initial sample mass and $\mathrm{m}(\mathrm{t})$ the sample mass after an immersion time t.

For each condition (temperature, pressure and thickness), 3 samples were weighed to ensure the reliability of the measurement.

\section{4. $T G A$}

Isothermal gravimetry measurements was performed with a SDT Q600 from TA Intruments at $120^{\circ} \mathrm{C}$ under $100 \mathrm{ml} / \mathrm{min}$ of $\mathrm{N}_{2}$. The mass evolution was followed for 120 minutes. 


\section{5. $D V S$}

A Dynamic Vapor Sorption (DVS 5000, TA Instruments) device was used to evaluate water diffusion coefficient in a 200 microns thick film at $80 \% \mathrm{RH}$ for temperatures ranging from $5^{\circ} \mathrm{C}$ to $60^{\circ} \mathrm{C}$. Although water diffusion coefficients have been measured under conditions different from those of ageing, these values are still interesting because the water diffusion kinetics in a polymer are not greatly affected by the value of partial pressure of the water in the external environment (except when clustering occurs). Water diffusion coefficents were calculated using equation below which is a simplification of the Fickian behavior in 1D case for $\mathrm{M}(\mathrm{t})<50 \%$

$$
\frac{M(t)}{M \infty}=\frac{4}{h} \sqrt{\frac{D * t}{\pi}}
$$

with $\mathrm{D}$ water diffusion coefficient $\left(\mathrm{m}^{2} / \mathrm{s}\right)$, h sample thickness $(\mathrm{m})$ and t time (s).

\subsection{Tensile Test}

Tensile test measurements were performed according to the ISO standard 527-1996 using a Tinius Olsen test machine, model H10K-T. Youngs modulus was measured at a crosshead displacement rate of $2 \mathrm{~mm} / \mathrm{min}$ using an extensometer, then yield and break were characterized at $50 \mathrm{~mm} / \mathrm{min}$. For each ageing condition, seven samples were tested and the results averaged.

\section{7. $D M A$}

Dynamic mechanical analysis was performed on a Metravib $150 \mathrm{~N}$ device. Measurements were performed in tensile mode at $1 \mathrm{~Hz}$ with an oscillation strain of $0.1 \%$ and a static force of $5 \mathrm{~N}$ on $10^{*} 5^{*} 20 \mathrm{~mm}^{3}$ samples. Heating rate was $2^{\circ} \mathrm{C} / \mathrm{min}$ between 25 and $300^{\circ} \mathrm{C}$.

\subsection{FTIR}

FTIR characterization was performed with a Perkin Elmer spectrometer using a $4 \mathrm{~cm}^{-1}$ resolution and 32 scans in ATR mode. 


\subsection{Solid State NMR}

NMR spectra were acquired at room temperature on a Bruker Avance III $500 \mathrm{MHz}$ spectrometer using a $4 \mathrm{~mm}$ MAS probehead. ${ }^{1} \mathrm{H}-{ }^{13} \mathrm{C}$ ramped $\mathrm{CP}-$ MAS (Cross-Polarization Magic Angle Spinning) spectra were obtained with a contact time of $1 \mathrm{~ms}$ under $1 \mathrm{H}$ decoupling during acquisition (spinal64, r.f. strength of $60 \mathrm{kHz}$ ). MAS frequency was set to $7100 \mathrm{~Hz}$ to avoid overlapping between signals and spinning sidebands. Recycle delay between scans was set to $1 \mathrm{~s}$. Chemical shifts were referenced relative to TMS at $0 \mathrm{ppm}$ using adamantane as a secondary reference.

\section{Results}

\subsection{Water absorption}

\subsubsection{Mass evolution}

Water diffusion characteristics in polymers (solubility and diffusivity) are usually characterized by weight gain measurements $[18,19]$. In the case of Fickian behaviour, the water uptake is proportional to the square root of time normalized by the sample thickness for short immersion time and then reaches a plateau [20].

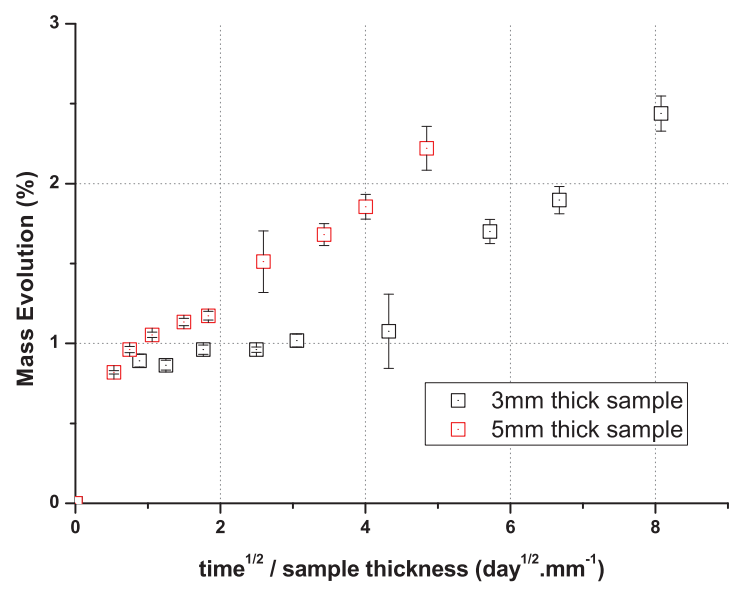

Figure 3: Mass evolution during ageing at $100^{\circ} \mathrm{C}$ in sea water

Figure 3 shows the mass evolution in seawater at $100^{\circ} \mathrm{C}$ as a function of the square root of time normalized by sample thickness. An unusual 
behaviour is observed, in fact sample mass increase rapidly to about $1 \%$ and seems to reach a plateau. But then, another increase of the mass appears, this may due to the superposition of different phenomena. In order to evaluate the actual water content within the polymer, destructive characterization by TGA has been performed.

\subsection{2. $T G A$}

To complete data from gravimetric method, an indirect measurement of the water content has been performed using TGA. In fact, figure 4 shows the mass evolution of an aged sample during isothermal heating at $120^{\circ} \mathrm{C}$ under nitrogen. The mass lost is due to water evaporation, and thus can be used to assess water content in an aged sample. Table 2 summarizes water contents in the material for different conditions. For all these conditions, the water content in the polymer is about $1 \%$.

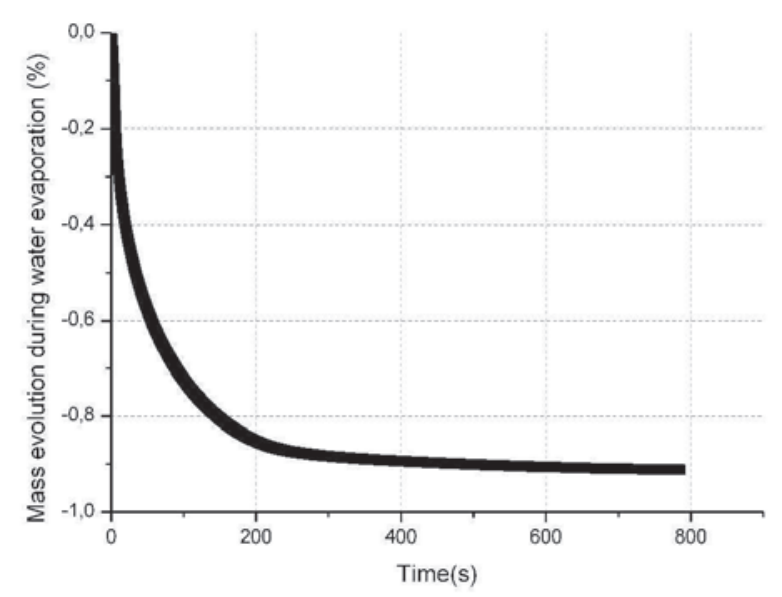

Figure 4: Mass evolution of an aged sample $\left(12\right.$ months at $\left.180^{\circ} \mathrm{C}\right)$ during water evaporation at $120^{\circ} \mathrm{C}$ under $\mathrm{N}_{2}$

\subsection{3. $D V S$}

Dynamic vapor sorption is a useful and accurate tool to assess water diffusivity in polymers. Figure 5 shows an example, the water absorption at $40^{\circ} \mathrm{C}$ at $80 \% \mathrm{RH}$. Figure 6 shows the evolution of the water diffusion coefficient as a function of temperature for the pDCPD. 


\begin{tabular}{|c|c|c|}
\hline Ageing Temperature & Duration $\mathbf{( m )}$ & $\mathbf{H}_{2} \mathbf{O}$ content $\mathbf{( \% )}$ \\
\hline 90 & 18 & 1.1 \\
100 & 18 & 0.9 \\
120 & 12 & 0.9 \\
160 & 18 & 0.8 \\
180 & 12 & 0.9 \\
\hline
\end{tabular}

Table 2: Water content in pDCPD after different ageing times and temperatures

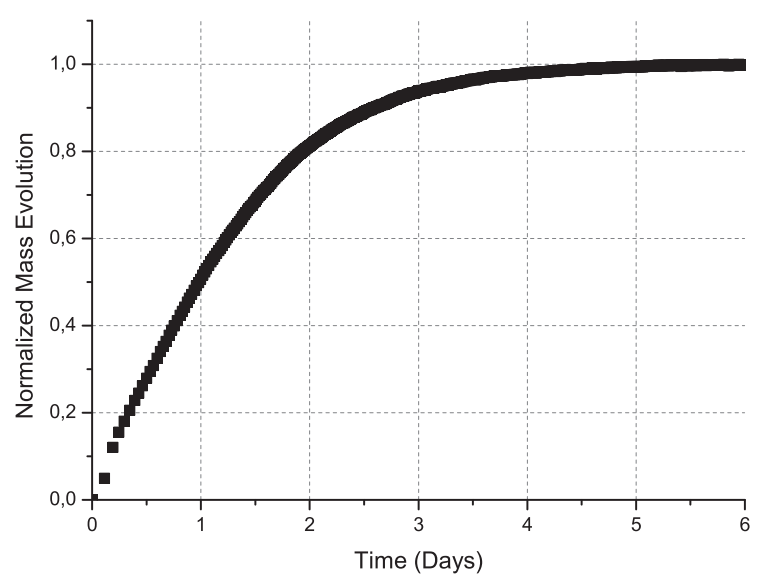

Figure 5: Mass evolution during water diffusion at $40^{\circ} \mathrm{C}$ in DVS

From these results (figure 6) we observe that water diffusion in $\mathrm{pDCPD}$ is $8.10^{-13} \mathrm{~m}^{2} / \mathrm{s}$ at $25 \mathrm{C}$. This is slow compared to $\mathrm{PU}$, in fact at $25^{\circ} \mathrm{C}$ water diffusion coefficient is about $7 \cdot 10^{-12} \mathrm{~m}^{2} / \mathrm{s}[21,22]$ and in the same range as for PP $\left(10^{-13}\right.$ and $10^{-11} \mathrm{~m}^{2} / \mathrm{s}$ for PP $[23,22]$ depending on crystallinity). For this temperature range, the water diffusion coefficient obeys an Arrhenius law with an activation energy (Ea) of $46.7 \mathrm{KJ} / \mathrm{mol}$. This is in accordance with published results where Ea is in the range between 30 and $60 \mathrm{KJ} / \mathrm{mol}$. It should be noted that this Arrhenius behavior may not be valid for higher temperatures, especially above $\mathrm{Tg}$ (i.e. $155^{\circ} \mathrm{C}$ ). 


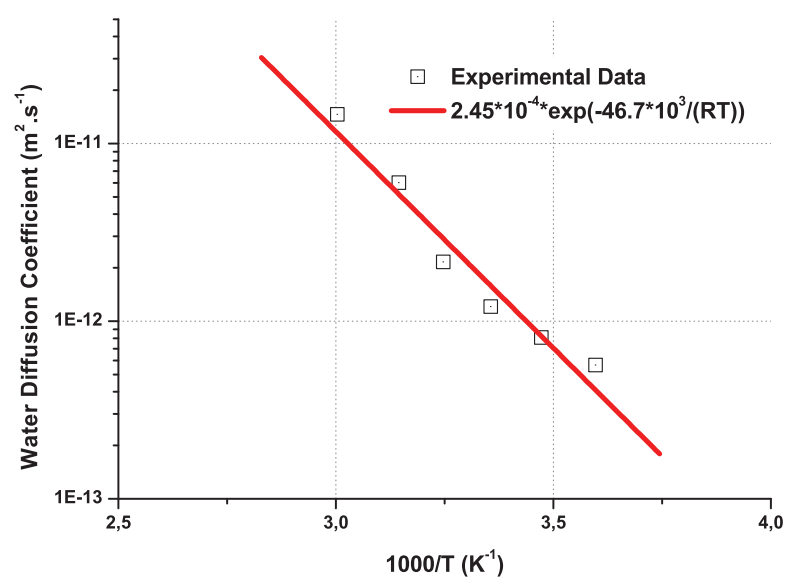

Figure 6: Water diffusion coefficient in $\mathrm{pDCPD}$ from $5^{\circ} \mathrm{C}$ to $60^{\circ} \mathrm{C}$

\subsection{Tensile behaviour}

Figure 7 shows the evolution of the tensile behaviour of the polymer during ageing at $90^{\circ} \mathrm{C}$ for different durations. In this case, ageing leads to a modification of mechanical properties such as stress at yield and elongation at break.

The evolution of the Youngs modulus, i.e. the slope of the stress/strain curve at the beginning (from 0 to $1 \%$ strain), as a function of ageing duration for different temperatures is plotted in figure 8. Small evolution of the modulus measured at $25^{\circ} \mathrm{C}$ is observed during the polymer ageing.

Figure 9 shows the evolution of the stress at yield and elongation at yield. Both values decrease during ageing in sea water for all ageing temperatures. Nevertheless we observe that during ageing above $\mathrm{Tg}$ the property loss is more important than for ageing below $\mathrm{Tg}$.

\section{3. $D M A$}

Figure 10 shows the evolution of the storage modulus with the temperature for aged samples at $90^{\circ} \mathrm{C}$ in sea water for different durations. For temperatures below $\mathrm{Tg}$, i.e. in the glassy state, there is no evolution of the modulus during ageing, this is in accordance with tensile test results. Nevertheless, in the rubbery state (i.e. above $\mathrm{Tg}$ ), an increase of the modulus is observed, this is a clear indication of an increase of the network density in the 


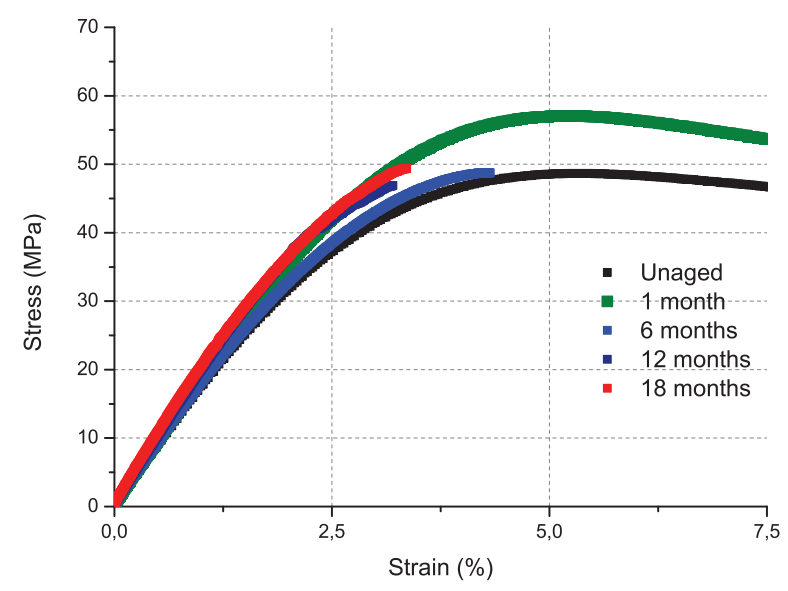

Figure 7: Tensile behavior evolution during ageing at $90^{\circ} \mathrm{C}$ in sea water

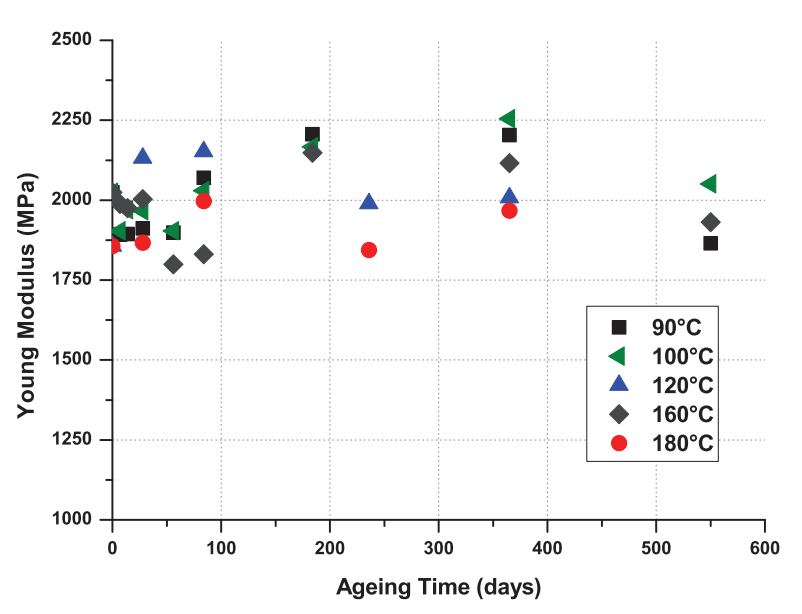

Figure 8: Evolution of Youngs modulus after ageing at different temperatures

polymer. The longer the ageing duration, the more significant the increases in rubbery modulus. At the same time, no significant evolution of the $\mathrm{Tg}$ is observed for this material during ageing at $90^{\circ} \mathrm{C}$.

Figure 11 shows DMA results for samples aged at $160^{\circ} \mathrm{C}$ in sea water. In the same way as for samples aged at $90^{\circ} \mathrm{C}$, no variation of the glassy 

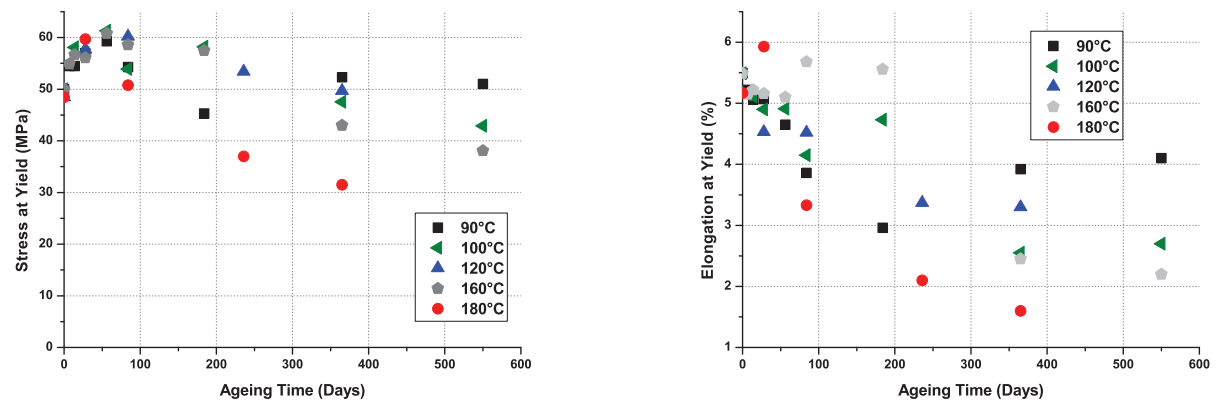

Figure 9: Evolution of the stress at yield and elongation at yield as a function of ageing time

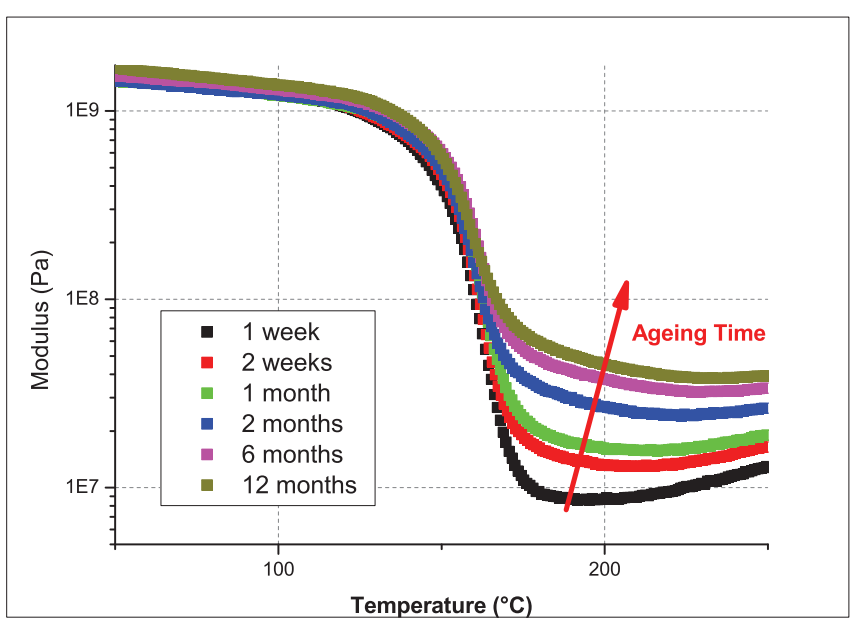

Figure 10: Evolution of the modulus with temperature for different ageing times in sea water at $90^{\circ} \mathrm{C}$

modulus and an increase of rubbery modulus are observed. Moreover, in this ageing condition, a large increase of the Tg is observed ; Figure 12 plots the evolution of $\mathrm{Tg}$ as a function of ageing conditions.

From DMA results, two different behaviours can be described, on one hand for ageing temperatures below $150^{\circ} \mathrm{C}$ there is no variation of the polymer $\mathrm{Tg}$ during ageing, but on the other hand for ageing temperatures above $150^{\circ} \mathrm{C}$ (i.e. 160 and $180^{\circ} \mathrm{C}$ ) there is a significant increase of the polymer $\mathrm{Tg}$ 


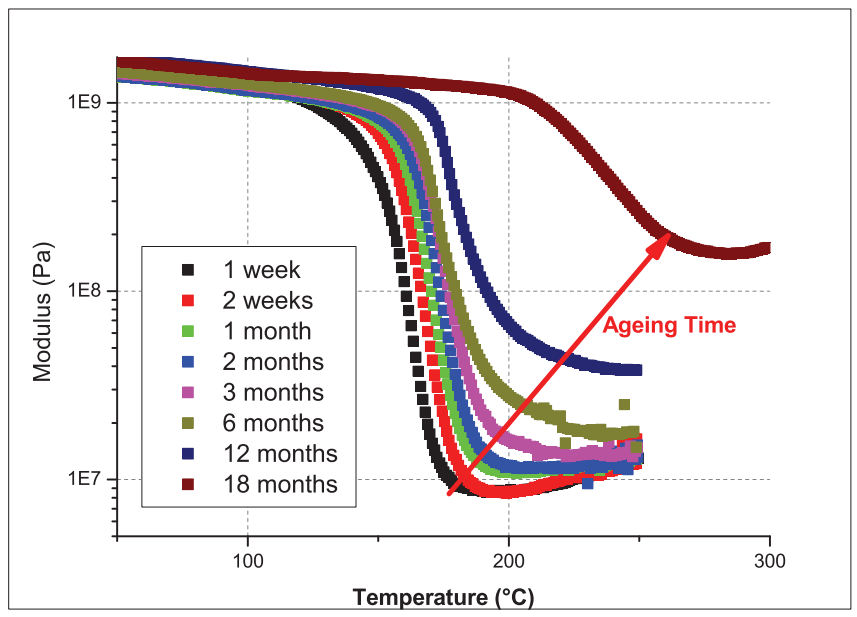

Figure 11: Evolution of the modulus with temperature after different ageing times in sea water at $160^{\circ} \mathrm{C}$

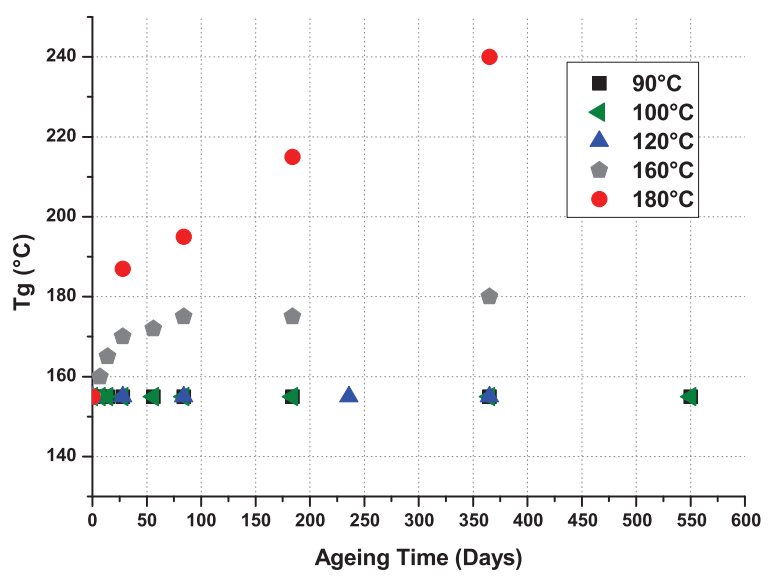

Figure 12: Evolution of the $\mathrm{Tg}$ during ageing at temperatures from $90^{\circ} \mathrm{C}$ to $180^{\circ} \mathrm{C}$

up to $250^{\circ} \mathrm{C}$.

To highlight possible heterogeneities in the thickness of aged samples some DMA measurements have been performed after sample surfacing. In fact, $0.5 \mathrm{~mm}$ has been removed from each side of some samples by polishing. 
Figure 13 shows DMA results obtained with a sample aged 18 months at $90^{\circ} \mathrm{C}$ before and after surfacing. After surfacing, the aged sample has the same properties as the unaged one. This is a clear indication that the polymer modification during ageing at $90^{\circ} \mathrm{C}$ is located only on the sample surface.

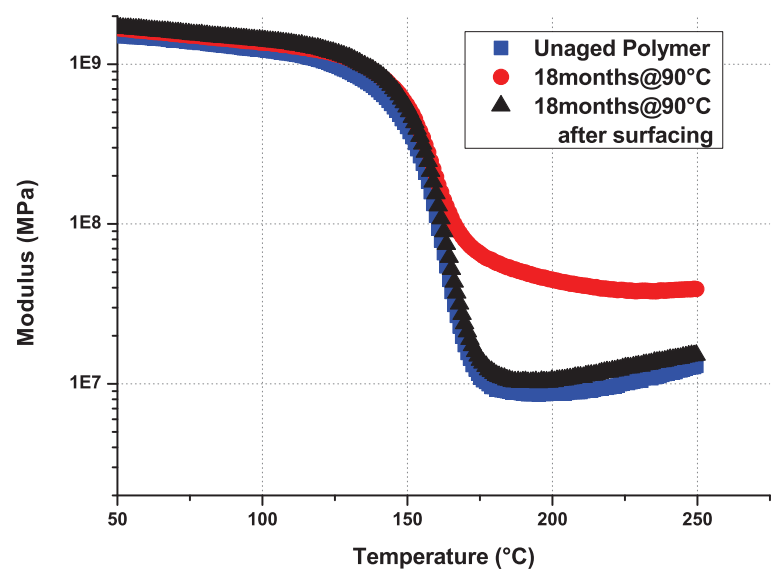

Figure 13: DMA results on samples aged at $90^{\circ} \mathrm{C}$ for 18 months before and after surfacing

In a similar way, DMA has been performed before and after surfacing on samples aged at $180^{\circ} \mathrm{C}$ for 14 months (Figure 14). In this case, the polymer modification is not located only on the surface of the sample but also in the bulk of the material.

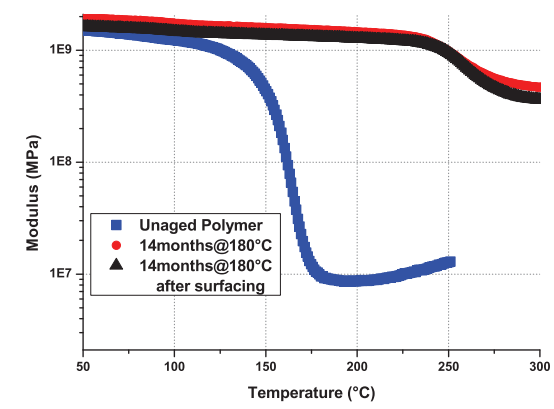

Figure 14: DMA results on samples aged at $90^{\circ} \mathrm{C}$ for 18 months before and after surfacing 
An increase of the rubbery modulus is observed during ageing due to an increase of the network density in the polymer. For ageing temperatures below $\mathrm{Tg}$, this increase is situated only on the sample surface, whereas for ageing temperatures above $\mathrm{Tg}$ the evolution is present throughout the bulk of the polymer.

\subsection{FTIR}

FTIR measurements have been performed in order to understand the chemical mechanisms involved in the polymer evolution when immersed in hot sea water. Figure 15 shows FTIR spectra at the surface of samples aged at $90^{\circ} \mathrm{C}$ for different durations. From these qualitative results the appearance of two new characteristic bands situated at $1100 \mathrm{~cm}^{-1}$ and $1750 \mathrm{~cm}^{-1}$ is observed, these bands are respectively attributed to $\mathrm{C}-\mathrm{O}$ and $\mathrm{C}=\mathrm{O}$. These evolutions are due to $\mathrm{pDCPD}$ oxidation $[24,4]$ as the modification of the regio $\mathrm{n} 980-960 \mathrm{~cm}^{-1}$ is attributed to the consumption of the carbon double bonds in the material. The hydroxyl increase observed at $3450 \mathrm{~cm}^{-1}$ is due to both oxidation and water content in the polymer.

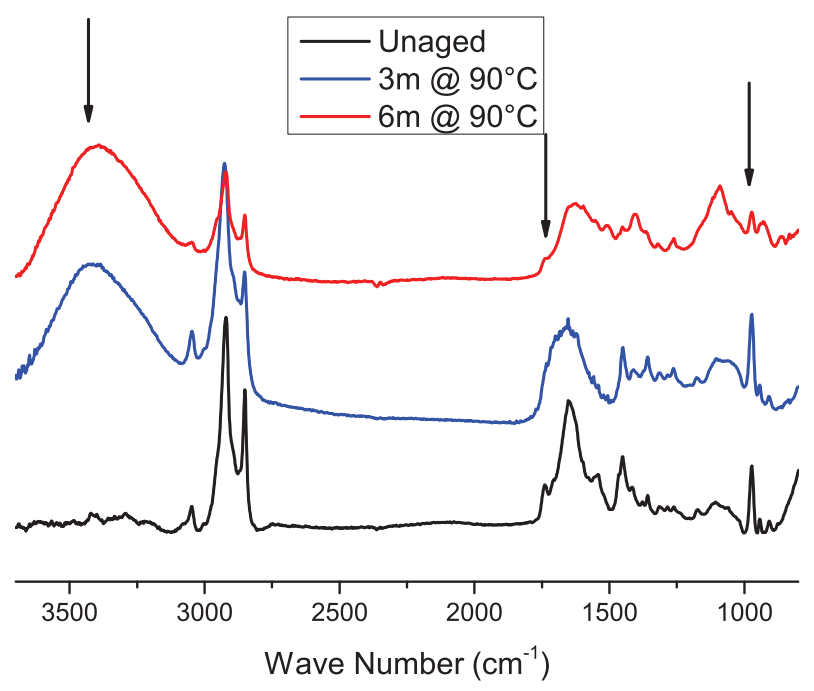

Figure 15: Evolution of the FTIR spectra as a function of ageing time

In order to evaluate the oxidised thickness, Infra Red measurements have 
been performed at different positions through the sample thickness. Figure 16 shows the evolution of the ratio of carbon double bonds (band at 970 $\mathrm{cm}^{-1}$ ) to $\mathrm{CH}_{2}$ (band at $2850 \mathrm{~cm}^{-1}$ ) and as a function of sample depth. A large decrease of the double bond content is observed in the first $0.25 \mathrm{~mm}$ from the sample surface (right side of figure 16).

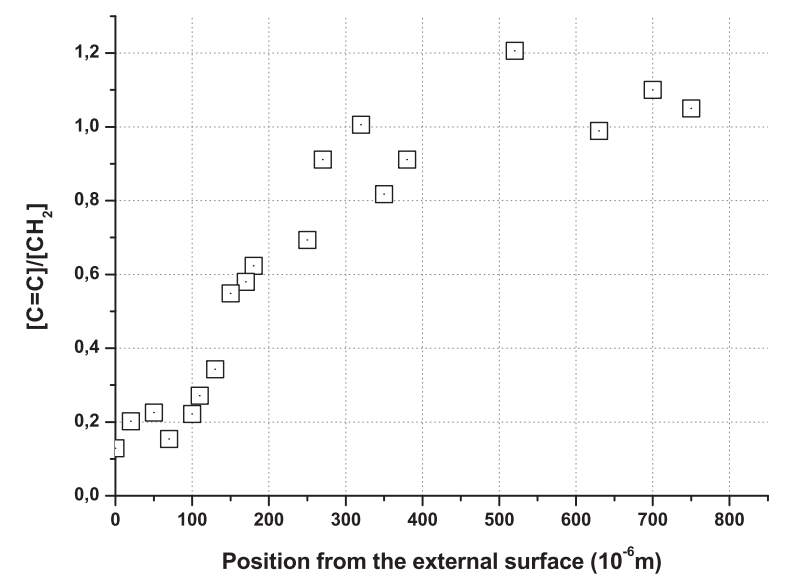

Figure 16: Evolution of the double bond content in thickness of a sample aged 18 months at $90^{\circ} \mathrm{C}$ in sea water (left side is in contact with water)

\subsection{Solid State NMR}

Because analysis of the chemical evolution of the polymer during ageing above $\mathrm{Tg}$ is not straightforward using FTIR results, solid state NMR has been performed on a sample aged for 12 months at $160^{\circ} \mathrm{C}$. Figure 17 shows ${ }^{13} \mathrm{C}$ CP-MAS NMR spectra before and after ageing. According to published work $[3,4]$, the peak attribution of the polymer can be proposed as shown in table 3.

Although there is not a large evolution of NMR spectra after ageing, an enlargement of peak situated at 42 and $52 \mathrm{ppm}$ is observed. This observation suggests an evolution of the carbon environment situated in C4 and C5 positions which could be explained by a reaction with the remaining double bonds according to figure 18 . 


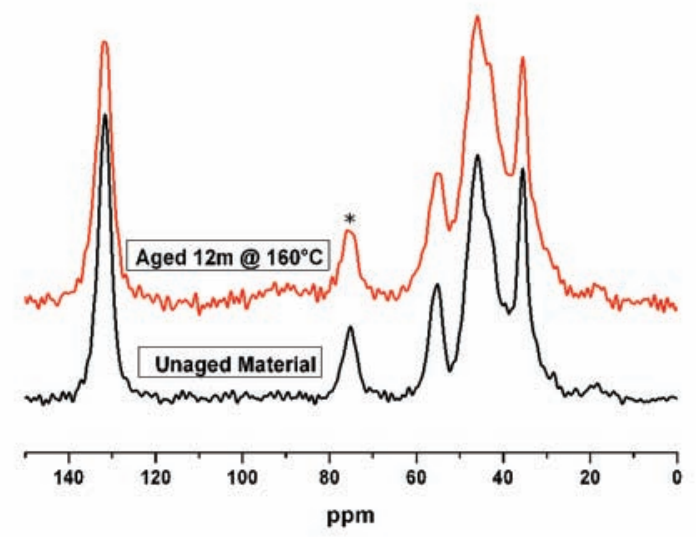

Figure 17: ${ }^{13} \mathrm{C}$ CP-MAS spectra before and after ageing at $160^{\circ} \mathrm{C}$ for 12 months (Star denotes MAS sideband)
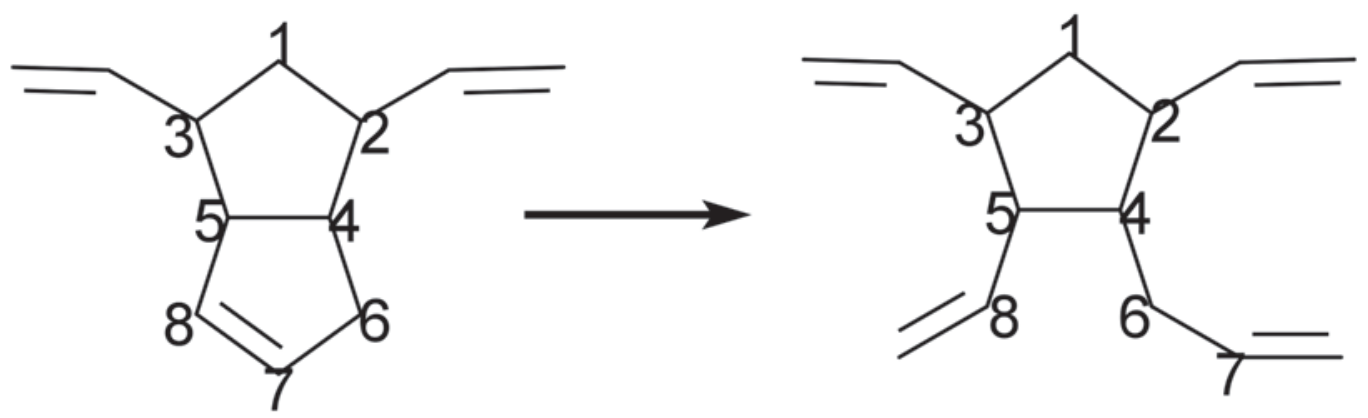

Figure 18: Possible reaction involved in the polymer degradation during ageing at temperature above $\mathrm{Tg}$

\section{Discussion}

\subsection{Ageing in sea water at temperature below $\mathrm{Tg}$}

The polymer absorbs about $1 \%$ of water when immersed in natural seawater, this absorption does not change the $\mathrm{Tg}$ of the polymer significantly. There is also no decrease of the Young modulus due to plasticizication effects of the material by water. 


\begin{tabular}{|c|c|}
\hline Signal (ppm) & Band Assignment \\
\hline 35 & C6 \\
\hline 42 & C4 \\
\hline 46 & C2+C3 \\
\hline 55 & C5 \\
\hline 131 & Carbon double bond \\
\hline
\end{tabular}

Table $3:{ }^{13} \mathrm{C}$ NMR peak attribution

When accelerated ageing is performed in sea water below $\mathrm{Tg}$, the main degradation mechanism in pDCDP is oxidation of the material. In fact, at high temperature, pDCPD undergoes oxidation leading to the formation of oxidation products such as carbonyl as observed by FTIR. During oxidation, there is also a reaction of radicals on the carbon double bond according to the reaction described in figure 19. This reaction leads to a reduction of the double bond content as a function of oxidation.

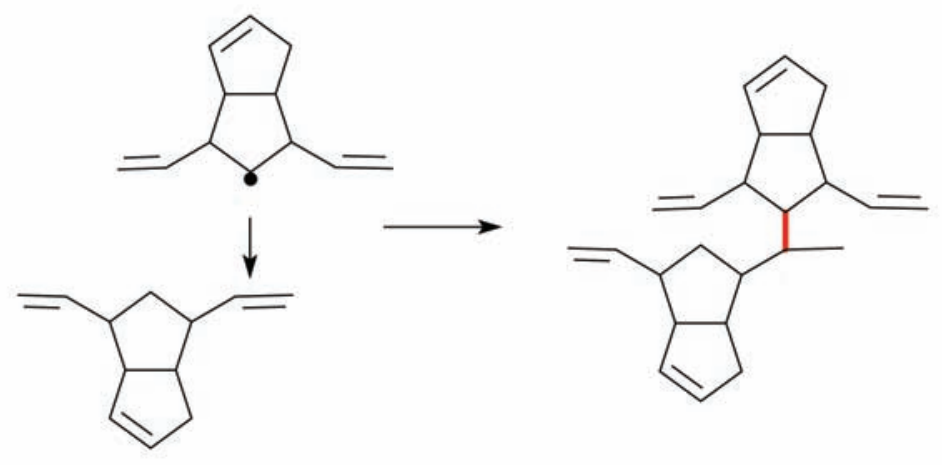

Figure 19: Possible reaction of radicals on double bond during oxidation

According to FTIR profiles it is clear that the oxidation at $90^{\circ} \mathrm{C}$ in seawater is limited to the first $0.25 \mathrm{~mm}$ from the exposed surface of the sample. This is due to a phenomenon named diffusion limited oxidation which has been reported many times $[25,26]$ and can be described in the following terms. If the diffusion of oxygen in the material is faster than the oxygen consumption due to polymer oxidation then the oxygen concentration, oxidation rate and thus oxidation level are homogenous throughout the sample thickness (case a in figure 20). On the other hand, if the oxygen consumption 
is faster than oxygen diffusion then there will be no oxygen in the bulk of the sample. Thus oxidation takes place only at the surface of the sample (case b in figure 20).
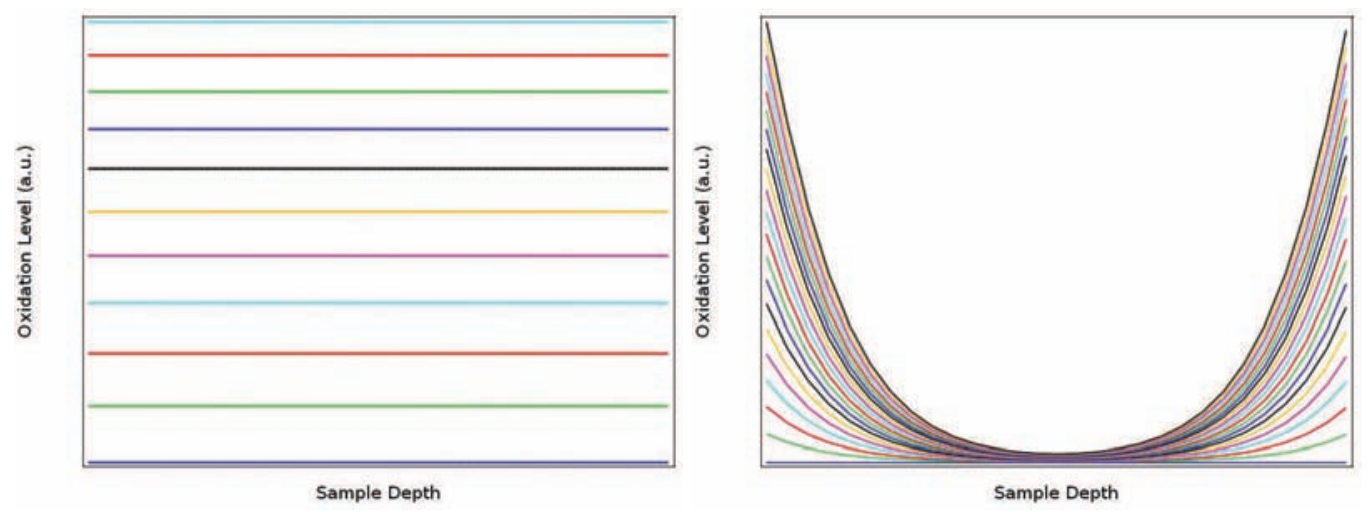

Figure 20: Schematic representation of the DLO effect (a: left, b: right)

When pDCPD undergoes oxidation, there is an increase of the polymer mass due to the incorporation of the oxgyen atoms. This behavior explains the unsual mass evolution observed during ageing in hot water (figure 3). Because of the reaction on the double bond, oxidation of pDCDP leads to a strong increase of the network density in the material. Furthermore it is well known that the modulus in the rubbery state is directly proportional to the network density of the polymer. As a result, ageing below Tg induces an increase of the rubbery modulus observed by DMA (figure 10). Due to the Difusion Limmtied Oxidation (DLO) effect, this increase is limited to $0.25 \mathrm{~mm}$ from the external surface for ageing at $90^{\circ} \mathrm{C}$ (figure 13 ). In terms of mechanical properties in the glassy state, the Youngs modulus is not affected by the oxidation of the material but a decrease of the elongation at break is observed. This is probably because the oxidized layer switches from a ductile to a fragile behaviour after ageing, and thus initiates polymer fracture more easily. When the oxidised layer is removed, the tensile behaviour of an aged sample $\left(14\right.$ months at $120^{\circ} \mathrm{C}$ ) reverts to that of the unaged one (figure 21 ).

\subsection{Ageing in sea water at temperature above $\mathrm{Tg}$}

In a similar way to that observed for lower temperature, the water absorption in this condition is low (about 1\%). It has to be noted that water diffusion is probably faster for temperatures above $\mathrm{Tg}$ due to an increase of 


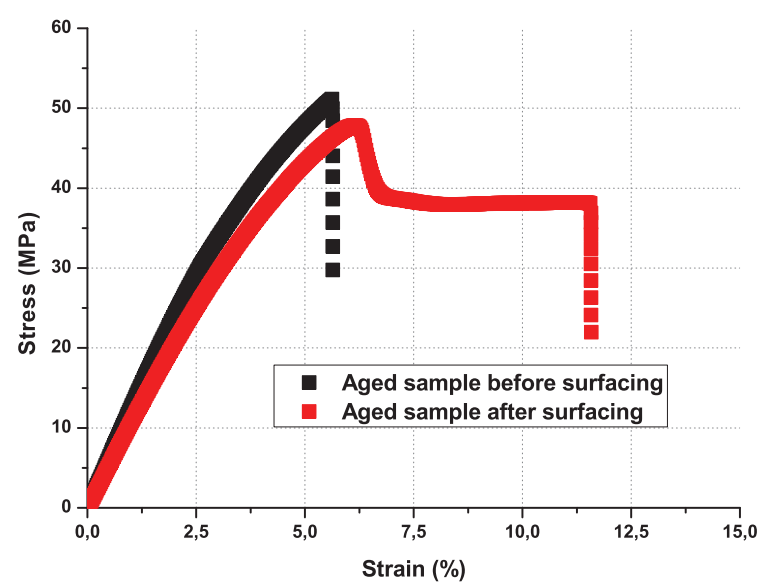

Figure 21: Tensile behavior of an aged sample $\left(14\right.$ months at $\left.120^{\circ} \mathrm{C}\right)$ with and without the oxidised layer

the mobility in the polymer. Unfortunately, the water diffusion coefficient is not straightforward to measure at these temperatures. For these ageing temperatures two different phenomena are involved in the polymer evolution : oxidation and crosslinking due to a secondary polymerization process. As for ageing below $\mathrm{Tg}$, oxidation occurs in the polymer. Although the diffusion of oxygen in the polymer is strongly increased by the ageing temperature above $\mathrm{Tg}$, the polymer oxidation occurs only at the surface due to a DLO effect. When temperature is above Tg there is secondary polymerization processg in the pDCPD. According to NMR results the main mechanism is probably a reaction on the residual carbon double bond after the methathesis, this is represented in figure 18. This secondary polymerization reaction results in a large increase of the polymer $\mathrm{Tg}$ (up to $250^{\circ} \mathrm{C}$ after 14 months at $180^{\circ} \mathrm{C}$ ) and also an imortant increase of the modulus in the rubbery state due to cross linking in the material. Unlike the oxidation, secondary polymerization process is due only to temperature (there is no diffusion effect) and is therefore homogeneous in the sample thickness. This explains the fact that polymer properties are not modified after removing the external layer (figure 15). In terms of tensile properties, there is a modification of the polymer behaviour at room temperature from ductile to brittle with the secondary polymerization process of the material, this kind of transition has been reported many 
time during polymer ageing $[27,28]$. Crosslinking of the polymer induces a reduction of the macromolecule capability to be stressed and thus a decrease of the elongation at break.

\section{Conclusion}

Accelerated ageing of polydicylpentadiene (pDCPD) has been performed in natural renewed sea water for up to 18 months at five different temperatures, from $90^{\circ} \mathrm{C}$ to $180^{\circ} \mathrm{C}$. Mechanical and chemical consequences of the degradation have been characterized and analysed. For ageing in sea water at temperatures below $\mathrm{Tg}$, the only mechanism involved in the degradation is oxidation. In this study, the oxidation is limited to the sample surface due to the competition between oxygen diffusion and reaction. Because of the presence of unsaturated bonds, oxidation leads to an increase of the network density in the polymer. This increase results in a modification of tensile behavior with a decrease of the stress and elongation at break. For ageing in sea water above $\mathrm{Tg}$, oxidation occurs but also secondary polymerization process $\mathrm{i}$ the polymer due to temperature exposure. This reaction leads to an increase of the pDCPD network density but in this case there is no spatial limitation due to diffusion. This reaction leads to a large increase of the polymer Tg but also a modification of the mechanical behavior at room temperature, the polymer shows a change from ductile to brittle behavior with ageing. In terms of field joint applications, this polymer does not undergo hydrolysis in water even at high temperature $\left(180^{\circ} \mathrm{C}\right)$. Water absorption is low in this polymer (about 1\%), so water will not affect the thermal conductivity of the coating significantly. The oxidation of the material, which is the only degradation mechanism during accelerated ageing below $\mathrm{Tg}$, will take place only if oxygen is present in the material at high temperature. Because of the temperature profile in the coating, oxygen diffusion in the coating will be limited by the diffusion at the external layer (i.e. at a temperature of $4^{\circ} \mathrm{C}$ ) thus the oxygen content in the field joint will be low. As a result, it appears that oxidation of the material will probably not be a problem for this application, this will be checked in future work by considering oxidation kinetics. For this application, the maximum service temperature is currently about $140^{\circ} \mathrm{C}$ but the in future if extracted oil reaches temperature above $\mathrm{Tg}\left(155^{\circ} \mathrm{C}\right)$ then $\mathrm{pDCPD}$ coating would undergo crosslinking. This reaction would lead to an embrittlement of the material and would need to be taken into account in the field joint design. 
For Field Joint applications PU is widely used because of the rapidity of processing, nevertheless this material has some limitations in terms of durability at high temperature (above $80^{\circ} \mathrm{C}$ ). When better durability at high temperature is required, polypropylene is used, but this results in an increase of the process time. Polydicyclopentadiene can be processed as fast as PU and exhibits better behavior in terms of durability in offshore conditions, and it therefore shows good potential for field joint applications.

\section{Ackowledgements}

The authors would like to thank Peter Davies for the careful reading of the paper.

\section{References}

\section{References}

[1] Matuszak ML, Frisch KC, Reegen SL. Hydrolysis of linear polyurethanes and model monocarbamates. Journal of Polymer Science: Polymer Chemistry Edition 1973;11(7):1683-90. doi: 10.1002/pol.1973.170110716.

[2] Chapman TM. Models for polyurethane hydrolysis under moderately acidic conditions: A comparative study of hydrolysis rates of urethanes, ureas, and amides. Journal of Polymer Science Part A: Polymer Chemistry 1989;27(6):1993-2005. doi:10.1002/pola.1989.080270620.

[3] Yang YS, Lafontaine E, Mortaigne B. Curing study of dicyclopentadiene resin and effect of elastomer on its polymer network. Polymer 1997;38(5):1121 -30. doi:10.1016/S0032-3861(96)00599-X.

[4] Yang YS, Lafontaine E, Mortaigne B. Nmr characterisation of dicyclopentadiene resins and polydicyclopentadienes. Journal of Applied Polymer Science 1996;60(13):2419-35.

[5] Gellert E, Turley D. Seawater immersion ageing of glass-fibre reinforced polymer laminates for marine applications. Composites Part A: Applied Science and Manufacturing 1999;30(11):1259 -65. doi:10.1016/S1359835X(99)00037-8. 
[6] Merdas I, Thominette F, Tcharkhtchi A, Verdu J. Factors governing water absorption by composite matrices. Composites Science and Technology 2002;62(4):487 -92. doi:10.1016/S0266-3538(01)00138-5.

[7] Xiao GZ, Shanahan MER. Water absorption and desorption in an epoxy resin with degradation. Journal of Polymer Science Part B: Polymer Physics 1997;35(16):2659-70.

[8] Zanni-Deffarges M, Shanahan M. Diffusion of water into an epoxy adhesive: comparison between bulk behaviour and adhesive joints. International Journal of Adhesion and Adhesives 1995;15(3):137 -42. doi: 10.1016/0143-7496(95)91624-F.

[9] Bordes M, Davies P, Cognard JY, Sohier L, Sauvant-Moynot V, Galy J. Prediction of long term strength of adhesively bonded steel/epoxy joints in sea water. International Journal of Adhesion and Adhesives 2009;29(6):595 - 608. doi:10.1016/j.ijadhadh.2009.02.013. ¡ce:title¿Special Issue on Durability of Adhesive Jointsi/ce:title ¿.

[10] Lefebvre, X. , Sauvant-Moynot , Choqueuse, D. , Chauchot, P. . Durabilité de mousses syntactiques utilisées en offshore profond : modélisation de la prise en eau des matériaux lors de vieillissements représentatifs et prévision de la flottabilité et de la conductivité thermique à long terme. Oil \& Gas Science and Technology - Rev IFP 2009;64(2):165-78. doi:10.2516/ogst/2008053.

[11] Le Duigou A, Davies P, Baley C. Seawater ageing of flax/poly(lactic acid) biocomposites. Polymer Degradation and Stability 2009;94(7):1151 -62. doi:10.1016/j.polymdegradstab.2009.03.025.

[12] Belan F, Bellenger V, Mortaigne B, Verdu J. Relationship between the structure and hydrolysis rate of unsaturated polyester prepolymers. Polymer Degradation and Stability 1997;56(3):301 -9. doi: 10.1016/S0141-3910(96)00203-0.

[13] Le Gac PY, Le Saux V, Paris M, Marco Y. Ageing mechanism and mechanical degradation behaviour of polychloroprene rubber in a marine environment: Comparison of accelerated ageing and long term exposure. Polymer Degradation and Stability 2012;97(3):288 -96. doi: 10.1016/j.polymdegradstab.2011.12.015. 
[14] Tsuji H, Suzuyoshi K. Environmental degradation of biodegradable polyesters 1. poly(-caprolactone), poly[(r)-3-hydroxybutyrate], and poly(l-lactide) films in controlled static seawater. Polymer Degradation and Stability 2002;75(2):347 -55. doi:10.1016/S0141-3910(01)00240-3.

[15] Rutkowska M, Krasowska K, Heimowska A, Steinka I, Janik H. Degradation of polyurethanes in sea water. Polymer Degradation and Stability 2002;76(2):233 -9. doi:10.1016/S0141-3910(02)00019-8.

[16] El-Mazry C, Correc O, Colin X. A new kinetic model for predicting polyamide 6-6 hydrolysis and its mechanical embrittlement. Polymer Degradation and Stability 2012;97(6):1049 -59.

[17] Davidson T, Wagener K. The polymerization of dicyclopentadiene: an investigation of mechanism. Journal of Molecular Catalysis A: Chemical 1998;133(12):67 - 74. doi:10.1016/S1381-1169(98)00091-0.

[18] Perrin F, Nguyen MH, Vernet J. Water transport in epoxyaliphatic amine networks influence of curing cycles. European Polymer Journal 2009;45(5):1524 -34. doi:10.1016/j.eurpolymj.2009.01.023.

[19] Pretsch T, Jakob I, Mller W. Hydrolytic degradation and functional stability of a segmented shape memory polyester urethane. Polymer Degradation and Stability 2009;94(1):61 - $73 . \quad$ doi: 10.1016/j.polymdegradstab.2008.10.012.

[20] Bellili A, David N, Vandame B, Wang Q, Goutille Y, Richaud E. Diffusion and solubility of mineral oils through ethylene vinyl acetate copolymer. Polymer Testing 2012;31(2):236 -47. doi: 10.1016/j.polymertesting.2011.11.003.

[21] Pissis P, Apekis L, Christodoulides C, Niaounakis M, Kyritsis A, Nedbal J. Water effects in polyurethane block copolymers. Journal of Polymer Science Part B: Polymer Physics 1996;34(9):1529-39.

[22] Bouchounneau N. Experimental testing and modelling of an industrial insulated pipeline for deep sea application. Ph.D. thesis; IFP; 2007.

[23] McKnight SH, Gillespie JW. In situ examination of water diffusion to the polypropylene-silane interface using ftir-atr. Journal of Applied Polymer Science 1997;64(10):1971-85. doi:10.1002/(SICI)10974628(19970606)64:10;1971::AID-APP12¿3.0.CO;2-0. 
[24] Perwuelz, A., Campagne, C. , Lam, T. M. . Caractérisation de la surface $\mathrm{du}$ polydicyclopentadiène (poly-dcpd) : influence du vieillissement sur le mouillage et l'adhésion de peinture. J Chim Phys 1999;96(5):904-22. doi:10.1051/jcp:1999178.

[25] Celina M, Wise J, Ottesen D, Gillen K, Clough R. Correlation of chemical and mechanical property changes during oxidative degradation of neoprene. Polymer Degradation and Stability 2000;68(2):171 -84. doi: 10.1016/S0141-3910(99)00183-4.

[26] Gillen KT, Clough RL. Rigorous experimental confirmation of a theoretical model for diffusion-limited oxidation. Polymer 1992;33(20):4358 -65. doi:10.1016/0032-3861(92)90280-A.

[27] Fayolle B, Audouin L, Verdu J. Oxidation induced embrittlement in polypropylene a tensile testing study. Polymer Degradation and Stability 2000;70(3):333 -40. doi:10.1016/S0141-3910(00)00108-7.

[28] Fayolle B, Audouin L, Verdu J. A critical molar mass separating the ductile and brittle regimes as revealed by thermal oxidation in polypropylene. Polymer 2004;45(12):4323 -30. doi:10.1016/j.polymer.2004.03.069. 